\title{
Halazepam Measurement
}

National Cancer Institute

\section{Source}

National Cancer Institute. Halazepam Measurement. NCI Thesaurus. Code C139078.

The determination of the amount of halazepam present in a sample. 